\title{
Feed Pellet and Corn Durability and Breakage During Repeated Elevator Handling
}

\author{
J. M. Boac, M. E. Casada, R. G. Maghirang
}

\begin{abstract}
Pelleting of animal feeds is important for improved feeding efficiency and for convenience of handling. Pellet quality impacts the feeding benefits for the animals and pellet integrity during handling. To compare the effect of repeated handling on the quality of feed pellets and corn, a 22.6-t (1000-bu) lot of feed pellets made from corn meal and a 25.4-t (1000-bu) lot of shelled corn, were each transferred alternately between two storage bins in the USDA-ARS, Grain Marketing and Production Research Center research elevator at Manhattan, Kansas, at an average flow rate of $59.4 \mathrm{t} / \mathrm{h}$. Samples from a diverter-type sampler were analyzed for particle size distribution (by sieving) and durability (by the tumbling box method). The apparent geometric mean diameter of pellet samples decreased with repeated transfers, whereas the mass of accumulated broken pellets increased with repeated transfers. The percentage of broken pellets increased by an average of $3.83 \%$ with each transfer from an initial value of $17.5 \%$, which was significantly different from the values obtained from shelled corn $(p<0.05)$ with an average increase of $0.38 \%$ per transfer. The durability index of feed pellets averaged $92.9 \%$ (standard deviation $=$ $0.6 \%)$ and did not change significantly $(p>0.05)$ during the transfers. The durability index of shelled corn was also not significantly different during the transfers. Analysis of dust removed by the cyclone separators showed that the mass of dust $<0.125 \mathrm{~mm}$ was significantly less for feed pellets (0.337 kg/t of pellet mass) than for shelled corn ( $0.403 \mathrm{~kg} / \mathrm{t}$ of corn mass).
\end{abstract}

Keywords. Breakage, Grain elevator, Repeated handling, Feed pellets, Shelled corn, Durability index, Dust, Broken pellets, Particle size.

$\mathrm{P}$ elleting of animal feed is important for improved efficiency in animal feeding and for convenience in feed handling. Research has shown that animals fed with good quality pellets have better growth performance and feed conversion than those fed with mash, reground pellets, or pellets with more fines (Jensen et al., 1962; Jensen and Becker, 1965; Kertz et al., 1981; Brewer et al., 1989; Zatari et al., 1990). Behnke (1994) indicated that improvements in animal performance have been attributed to decreased feed wastage, reduced selective feeding, decreased ingredient segregation, less time and energy expended for eating, destruction of pathogens, thermal modification of starch and protein, and improved palatability. A significant part of the improvement is related to the quality of the pellet. Good quality pellets are needed to withstand repeated handling processes and reduce the formation of fines by mechanical action during transport.

Submitted for review in December 2007 as manuscript number FPE 7298; approved for publication by the Food \& Process Engineering Institute Division of ASABE in June 2008.

Mention of trade names or commercial products in this article is solely for the purpose of providing specific information and does not imply recommendation or endorsement by the U.S. Department of Agriculture.

The authors are Josephine Mina-Boac, ASABE Member Engineer, Graduate Student, Department of Biological and Agricultural Engineering, Kansas State University, Manhattan, Kansas; Mark E. Casada, ASABE Member Engineer, Lead Scientist, Agricultural Engineer, USDA-ARS Grain Marketing and Production Research Center, Engineering Research Unit, Manhattan, Kansas; and Ronaldo G. Maghirang, ASABE Member Engineer, Professor, Department of Biological and Agricultural Engineering, Kansas State University, Manhattan, Kansas. Corresponding author: Mark E. Casada, USDA-ARS GMPRC, ERU, 1515 College Ave., Manhattan, KS 66502; phone: 785-776-2758; fax: 785-537-5550; e-mail: casada@ksu.edu.
The quality of the pellets may be described by their durability and resistance to attrition and/or breakage during handling. Gustafson (1959) classified the forces acting on the pellets as impact, compression, and shear. Impact forces shatter the pellet surface and any natural cleavage planes in the pellet. Compression forces crush the pellet and also cause failure along cleavage planes. Shear forces cause abrasion of the edges and surface of the pellet.

Several laboratory methods have been developed to measure the durability of pellets. The tumbling box, which is popular in North America and is the basis for ASAE Standard S269.4 (ASAE Standards, 2003a), uses $500 \mathrm{~g}$ of prescreened pellets placed in a box that revolves for $10 \mathrm{~min}$ at $50 \mathrm{rpm}$ (Young, 1962). The DURAL tester, which was developed for hard alfalfa pellets, subjects $100 \mathrm{~g}$ of pellets to impact and shear forces for $30 \mathrm{~s}$ at $1600 \mathrm{rpm}$ (Larsen et al., 1996; Sokahnsanj and Crerar, 1999; Adapa et al., 2004). The Lignotester uses a sample of $100 \mathrm{~g}$ of pellets and blows them around a perforated chamber for $30 \mathrm{~s}$ (Winowiski, 1998). In all of these methods, the Pellet Durability Index (PDI) was calculated as the percentage of the mass of surviving pellets over the total mass of pellets.

Aarseth (2004) studied the susceptibility of feed pellets for livestock to attrition during pneumatic conveying. He investigated the effects of air velocity, bend radius, and number of repeated impacts for three commercially available feeds in a 100-mm-diameter pipeline. The three commercial feeds were produced by Felleskjøpet (Kambo, Norway). Feeds 'Formel Favør 30' (FF30) and 'Formel Elite' (FE) had pellet diameters of $6 \mathrm{~mm}$ and were formulated for ruminants, whereas, 'Kombi Norm' (KN) had a smaller pellet diameter $(3 \mathrm{~mm})$ and was formulated for pigs. He used Weibull analysis to assess pellet quality. This analysis incorporates fracture mechanics with statistics in order to describe the 
strength of brittle materials. Brittle materials show high scatter in strength due to variation in crack or flaw sizes, called Griffith cracks. Weibull analysis considers a relationship between the scatter in fracture strength and the size distribution of Griffith cracks. Aarseth and Prestløkken (2003) demonstrated that this method can be applied to feed pellets for ruminants and swine. Aarseth (2004) used the same method to analyze the three commercial pellets mentioned earlier.

Repeated handling in an elevator affects pellet breakage and quality. Repeated handling data for feed pellets in an elevator will be valuable for feed handlers in evaluating and improving their feed handling and transportation procedures. Corn-based feed pellets incorporated with other feed ingredients to improve its nutritive value can be an alternative to shelled corn.

Previous studies have been conducted on the durability of corn during handling. Baker et al. (1986) found that breakage susceptibility of shelled corn increased significantly during handling in pneumatic conveying systems with approximately 100-mm-diameter pipe. Tests involved using total lengths of 31 to $60 \mathrm{~m}$, with two to four 90-degree elbows with a $1.22-\mathrm{m}$ radius of curvature.

Foster and Holman (1973) studied physical damage (breakage) to corn, wheat, soybeans, and dry edible peas by commercial handling methods. Commercial handling methods included in their study were dropping products by free fall (simulating bin filling), dropping products through a spout (simulating railcar filling), grain-throwing (simulating the loading of barges and ship holds), and handling products in a bucket elevator. They enumerated the variables involved in corn breakage caused by commercial handling, namely: free fall height, impact surface, and corn moisture content and temperature. Corn that dropped from a height of $12 \mathrm{~m}$ onto corn in the commercial handling study caused $4.3 \%$ breakage for corn with $12.6 \%$ moisture at $-3.8^{\circ} \mathrm{C}$, and $0.25 \%$ breakage for corn with $15.2 \%$ moisture at $-5.0^{\circ} \mathrm{C}$. It was also observed that breakage of corn handled decreased at higher grain temperatures.

Data on repeated handling of shelled corn in the USDA-ARS, Grain Marketing and Production Research Center (GMPRC) research elevator at Manhattan, Kansas have been reported. Martin and Stephens (1977) repeatedly transferred corn alternately between two bins. Percentage of breakage of corn kernels increased linearly during the repeated-handling tests. They observed breakage within the range reported by Foster and Holman (1973). The corn had a fall similar to the average 16-m free fall in bins 1 and 2 . It had a moisture content of about $13 \%$ and a temperature of $11^{\circ} \mathrm{C}$. A constant increase in breakage during 20 repeated transfers was also observed, in line with the observation of Foster and Holman (1973).

Martin and Lai (1978) reported values of $0.080 \%$, $0.037 \%$, and $0.028 \%$ for dust $<0.125 \mathrm{~mm}$ generated per transfer for corn, sorghum, and wheat, respectively, with a similar handling system. Converse and Eckhoff (1989) observed linear increases in broken corn and fine materials during repeated handling of six lots of corn that had been subjected to different drying treatments. The rates of increase were generally higher for corn dried at higher temperatures. Total dust emission per transfer varied from $0.084 \%$ to $0.21 \%$ of the total mass with the greater emission associated with corn dried at higher temperatures.
The objective of this study was to compare the effect of repeated handling in an elevator on the quality of feed pellets and shelled corn. The measures of quality included percentage of broken materials, PDI, and dust generated. The feed pellets in this study were compared to shelled corn due to the manufacturer's interest in making this pellet as a direct alternative to corn.

\section{Materials ANd Methods}

\section{Test Facility AND Materials}

Tests were performed in the research grain elevator at the USDA-ARS, GMPRC (Manhattan, Kans.), which has a storage capacity of $1,400 \mathrm{t}(55,000 \mathrm{bu})$. The elevator has one receiving pit and two bucket elevator legs, each with a maximum feed rate of $81.6 \mathrm{t} / \mathrm{h}(3,000 \mathrm{bu} / \mathrm{h})$. It is equipped with a pneumatic dust-control system, including cyclone separators (fig. 1). In this research, the system was operated so that the airflow rate through the upper cyclone separators was $5.0 \mathrm{~m}^{3} / \mathrm{s}$ and that through the lower cyclone separators was $6.4 \mathrm{~m}^{3} / \mathrm{s}$. These settings were the typical operating conditions for the elevator.

Tests were conducted with $22.6 \mathrm{t}$ of feed pellets and $25.4 \mathrm{t}$ of shelled corn. The mass of pellets and corn was determined

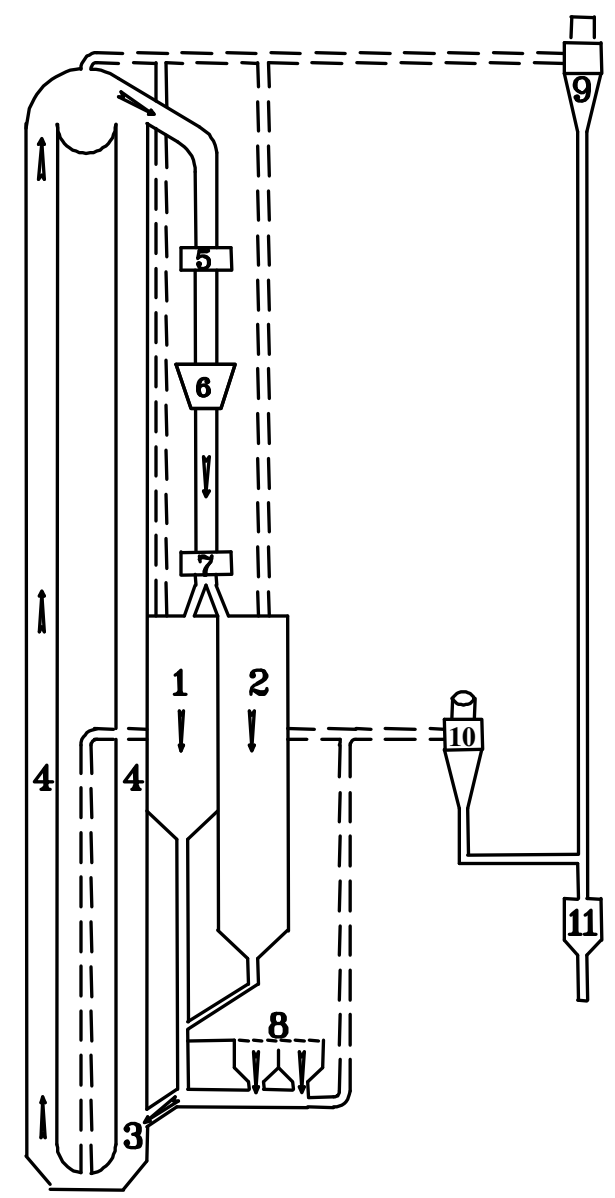

Figure 1. Schematic diagram of the USDA-ARS-GMPRC research elevator, showing the flow of the handled materials and location of equipment (not drawn to scale): 1 - storage bin 1, 2 - storage bin 2, 3 - elevator boot, 4 - elevator legs, 5 - diverter-type (DT) sampler, 6 - hopper, 7 - distributor, 8 - receiving area, 9 - upper cyclone separators, 10 - lower cyclones separators, and 11 - dust bin. 
by weighing the delivery truck containing the material before and after unloading in the elevator receiving area. During unloading, samples were taken every 2.5 min with a pelican sampler. These initial samples were labeled as Transfer 0 . The materials were then moved from the receiving pit by belt conveyor and were bucket elevated and dropped into bin 1 for storage before testing (fig. 1).

The feed pellets were made of corn meal, with a moisture content of $13.2 \%$ wet basis (wb) after pelleting. The crude fat/oil, protein, and starch contents were $1.53 \%, 8.55 \%$, and $65.6 \%$, respectively. The pellets had an initial bulk density of $644 \mathrm{~kg} / \mathrm{m}^{3}$, nominal diameter of $6.40 \mathrm{~mm}$, average pellet length of $10.5 \mathrm{~mm}$ [standard deviation $(\mathrm{SD})=1.2 \mathrm{~mm}$ ], and initial moisture content of $10.5 \%$ wb [with mean moisture content of $10.4 \%(0.213 \%)$ wb for eight transfers]. The shelled corn was U.S. Grade No. 2, with the following initial properties: test weight, $753 \mathrm{~kg} / \mathrm{m}^{3}$; broken corn and foreign materials (BCFM), 3.13\%; geometric mean diameter (GMD), $6.91 \mathrm{~mm}$; and moisture content, $12.6 \% \mathrm{wb}$ [with mean moisture content of $12.6 \%(0.284 \%)$ wb for eight transfers].

\section{Test Procedure}

\section{Elevator Transfers and Sampling}

Figure 1 shows a schematic diagram of the material flow during the test. The material was transferred alternately between storage bin 1 (with a volume of approximately $85 \mathrm{~m}^{3}$ and a depth of $20 \mathrm{~m}$ ) and bin 2 (with a volume of approximately $411 \mathrm{~m}^{3}$ and depth of $26 \mathrm{~m}$ ). From storage bin 1 , the material descended by gravity through spouts and entered the boot on the descending side of the bucket elevator. The bucket elevator raised it $54.9 \mathrm{~m}$, where it was discharged through a spout. It descended $3.0 \mathrm{~m}$ to pass through an automatic diverter-type (DT) sampler (CarterDay Co., Minneapolis, Minn.). The material then descended $1.5 \mathrm{~m}$ to a hopper, and then another $3.0 \mathrm{~m}$ to the distributor, before it descended $4.6 \mathrm{~m}$ to enter storage bin 2 and then fell to the bottom of the bin. Transfer from bin 1 to bin 2 constituted one transfer and one-half of a cycle.

From storage bin 2, the material was spouted by gravity to the belt conveyor, descended $3.0 \mathrm{~m}$ to enter the boot, elevated $54.9 \mathrm{~m}$ before it descended and passed through the DT sampler, descended again to the hopper, and then to the distributor, and finally back to storage bin 1 . This second transfer completed one cycle. A total of six transfers, or three cycles, at an average material flow rate of $62.2 \mathrm{t} / \mathrm{h}$ (range: 52.7 to $68.6 \mathrm{t} / \mathrm{h}$ ) for feed pellets and $56.6 \mathrm{t} / \mathrm{h}$ (range: 51.4 to $65.1 \mathrm{t} / \mathrm{h}$ ) for shelled corn, were done initially. In both cases the material was left in bin 1 for one week before it was again transferred to bin 2. It was left for one more week in bin 2 before the eighth and final transfer back to bin 1 . This scenario was selected because it simulated the number and type of transfers in a typical handling process for the feed pellets.

Each transfer was designated serially from Transfer 1 to Transfer 8. Samples were taken every 2.5 min during each transfer with the DT sampler. An average of nine samples were taken during each transfer, with a mean sample mass of $642 \mathrm{~g}(\mathrm{SD}=51.9 \mathrm{~g})$ for the feed pellets. An average of 10 samples were obtained from shelled corn per transfer, with a mean sample mass of $679 \mathrm{~g}(\mathrm{SD}=42.5 \mathrm{~g})$.
Material samples during receiving (Transfer 0) and those from Transfers 1 to 8 were divided appropriately with a Boerner divider for particle sizing $(100 \mathrm{~g})$, durability measurement (500 g), and moisture-content determination (25 $\mathrm{g}$ for pellet; $15 \mathrm{~g}$ for corn). A $250 \mathrm{~g}$ portion of each shelled corn sample was also separated for BCFM determination. Samples were placed in sealed plastic bags and stored inside sealed plastic buckets at $4^{\circ} \mathrm{C}$ in a refrigerated room for subsequent analyses for particle size distribution, durability index, and moisture content.

\section{Particle Sizing}

The 100-g portions of each material sample were sieved in accordance with ASAE Standard S319.3 (ASAE Standards, 2003b) by using a Ro-Tap RX-29 sieve shaker (W.S. Tyler, Mentor, Ohio). The screen sizes were U.S. Standard sieve screen size openings: $8.00,6.70,6.30,5.60,3.35,1.70$, $1.00 \mathrm{~mm}$, and pan $(0.850 \mathrm{~mm})$, which was adjusted from the screen sizes in ASAE Standard S319.3 to accommodate larger pellet sizes. Samples were initially sieved and shaken until they reached endpoint (ASAE Standards, 2003b). Endpoint was determined by comparing the mass on each sieve at 1-min intervals after an initial sieving time of $10 \mathrm{~min}$. If the mass on the smallest sieve containing any of the pellets changed by $0.1 \%$ or less of the material mass during a 1 -min period, then sieving was considered complete. In accordance with ASAE Standard S269.4 (ASAE Standards, 2003a), feed pellet samples passing through the 5.60 -mm-mesh sieves were considered broken pellets. Pellets that were retained on sieve sizes $6.70,6.30$, and $5.60 \mathrm{~mm}$ were considered whole pellets. Shelled corn samples passing through the $4.76-\mathrm{mm}$ round-hole sieve (12/64-in.) were considered broken corn and those that were retained on the $4.76-\mathrm{mm}$ round hole sieve were considered whole corn (USDA-GIPSA, 2004). Samples were weighed on a digital balance (O-Haus Adventurer Pro AV 4101, O-Haus Corp., Pine Brook, N.J.) with a resolution of $0.1 \mathrm{~g}$.

From the particle size distribution data, the GMD of the particles by mass, geometric standard deviation by mass (GSD), and geometric standard deviation of particle diameter by mass $\left(\mathrm{GSD}_{\mathrm{w}}\right)$ were calculated (ASAE Standards, 2003b).

\section{Durability Measurement}

The durability of the pellets was evaluated by using a durability tester in accordance with ASAE Standard S269.4 (ASAE Standards, 2003a). Samples from Transfers 0 (initial), 1 (first), 4 (middle), and 7 (second to last) were selected for the durability test. The durability tester consisted of four 130-mm wide tumbling boxes. The device was rotated about an axis perpendicular to, and centered in, the $300-\mathrm{mm}$ sides. A 230-mm-long baffle was affixed symmetrical to a diagonal of one 300- $\times 300-\mathrm{mm}$ side inside the box.

With four tumbling boxes, four samples were tested simultaneously. Four 500-g samples from each of Transfers $0,1,4$, and 7 were selected as specified by ASAE Standard S269.4 (ASAE Standards, 2003a) for pellets with a nominal diameter of $6.40 \mathrm{~mm}$. The samples (i.e., pellets greater than $5.60 \mathrm{~mm}$ ) were tumbled for $10 \mathrm{~min}$ at $50 \mathrm{rpm}$. Immediately after tumbling the samples were removed and sieved with the $5.60-\mathrm{mm}$ screen for approximately $30 \mathrm{~s}$ to remove the fines and broken pellets. The pellets that were retained on the sieve were weighed. A similar procedure was used for shelled corn 
from Transfers $0,1,4$, and 7, using the standard 4.76-mm round-hole sieve to screen the whole kernels and determine broken kernels before and after tumbling. The durability index was computed by using:

$$
\begin{aligned}
& \text { Durability Index }= \\
& \text { mass of material retained } \\
& \text { on the sieve after tumbling } \\
& \hline \text { mass of material before tumbling }
\end{aligned}
$$

Durability index (DI) was calculated for both pellets and shelled corn. For pellets the durability index is commonly known as PDI, a term retained in this article.

Moisture content of the feed pellet samples was determined by oven-drying at $60^{\circ} \mathrm{C}$ for $72 \mathrm{~h}$ according to ASAE Standard S358.2 (ASAE Standards, 2003c) as indicated in ASAE Standard S269.4 (ASAE Standards, 2003a). Moisture content of shelled corn was determined by oven-drying at $103^{\circ} \mathrm{C}$ for $72 \mathrm{~h}$ according to ASAE Standard S352.2 (ASAE Standards, 2003d).

\section{Dust Sampling}

Handling of the materials generated dust. The pneumatic dust control system collected the dust through the cyclone separators and into the dust bin (fig. 1). After each transfer, the dust collected in the dust bin was emptied into a plastic bag, weighed, labeled, and stored at $4^{\circ} \mathrm{C}$ in a refrigerated room for later analysis. Representative dust samples from the plastic bag were obtained in accordance with ASTM Standard E-300 (ASTM Standards, 2000). Nine samples from the plastic bag from each transfer were obtained by using a grain sampling probe. The samples were sieved with a U.S. Sieve No. 120 (0.125 mm). Particles collected by the cyclones that passed through the $0.125-\mathrm{mm}$ sieve aperture (ca. 0.01 to $0.125 \mathrm{~mm}$ ) (Martin and Sauer, 1976; Martin and Stephens, 1977; Martin and Lai, 1978) were weighed.

\section{Data Analyses}

The experiment was designed with repeated handling (transfers) and materials as the class variables. The experimental units were the feed pellets and the corn. This design was devised to control the cost involved in conducting this large-scale experiment.
Comparisons of results between materials (feed pellets and shelled corn) and between transfers (Transfer 1 to 8) were done by using Analysis of Variance (ANOVA) in SAS (SAS Institute Inc., Cary, N.C.). The percentage of dust for the eight transfers in this study was compared with published data on corn (Martin and Stephens, 1977) by using the ANOVA procedure in SAS.

\section{Results AND Discussion \\ Particle Size Distribution}

The initial GMD of the pellets was $5.62 \mathrm{~mm}$ (table 1). The apparent GMD decreased as the number of transfers increased. From Transfers 0 to 4, GMD decreased by approximately $1.9 \mathrm{~mm}$; from Transfers 4 to 8 , the GMD remained relatively constant. For shelled corn, the initial GMD was $6.91 \mathrm{~mm}$ (table 1). The apparent GMD for shelled corn did not differ among transfers, except with Transfer 0 . The apparent GMD, GSD, and $\mathrm{GSD}_{\mathrm{w}}$ of the pellets were significantly different $(\mathrm{p}<0.01)$ from that of shelled corn.

\section{Whole ANd Broken MATERIALS}

No pellets were retained on the $8.00-\mathrm{mm}$ sieve. The mass percentage of whole pellets $(\geq 5.60 \mathrm{~mm}$ ) decreased with subsequent transfers, from $82.5 \%$ to $49.8 \%$ (fig. 2). This was due to pellet breakage occurring during transfers. As expected, the mass of broken pellets $(<5.60 \mathrm{~mm})$ increased with subsequent transfers. The mass percentage of broken pellets increased from an initial value of $17.5 \%$ to $50.2 \%$, equivalent to an average of $3.83 \%$ increase with each transfer (table 1). The nonlinear increase in breakage differed from the linear increase observed by Foster and Holman (1973) and Martin and Stephens (1977) for shelled corn.

For the shelled corn in this study, the mass percentage of whole corn ( $\geq 4.76 \mathrm{~mm}$ ) from Transfer 0 differed from all the other transfers. The mass percentage of whole corn decreased from $96.9 \%$ to $93.8 \%$ and the mass percentage of broken corn $(<4.76 \mathrm{~mm})$ increased from $3.13 \%$ to $6.18 \%$ for the eight transfers. The mass percentage of broken corn increased by an average value of $0.38 \%$, which was significantly less $(\mathrm{p}<0.05)$ than that of the pellets (table 1$)$.

\begin{tabular}{|c|c|c|c|c|c|c|c|c|}
\hline \multirow[b]{2}{*}{ Transfer } & \multicolumn{2}{|c|}{ Apparent GMD (mm) } & \multicolumn{2}{|c|}{ GSD } & \multicolumn{2}{|c|}{ Apparent GSDw (mm) } & \multicolumn{2}{|c|}{ Change in $\%$ Breakage } \\
\hline & Feed Pellets & Corn & Feed Pellets & Corn & Feed Pellets & Corn & Feed Pellets & Corn \\
\hline 0 & 5.62 & 6.91 & 1.69 & 1.28 & 3.09 & 1.74 & & \\
\hline 1 & 5.01 & 6.69 & 1.88 & 1.35 & 3.38 & 2.04 & 7.42 & 1.72 \\
\hline 2 & 4.55 & 6.75 & 2.00 & 1.31 & 3.42 & 1.83 & 7.29 & 0.315 \\
\hline 3 & 4.54 & 6.67 & 1.99 & 1.37 & 3.38 & 2.11 & 0.543 & -0.066 \\
\hline 4 & 3.71 & 6.70 & 2.19 & 1.32 & 3.22 & 1.90 & 12.90 & -0.308 \\
\hline 5 & 3.90 & 6.62 & 2.10 & 1.38 & 3.16 & 2.15 & -0.992 & 0.401 \\
\hline 6 & 3.87 & 6.68 & 2.12 & 1.34 & 3.19 & 1.98 & -0.048 & 0.051 \\
\hline 7 & 3.60 & 6.58 & 2.14 & 1.37 & 3.02 & 2.13 & 5.58 & 1.02 \\
\hline 8 & 3.81 & 6.56 & 2.09 & 1.37 & 3.06 & 2.09 & -2.02 & -0.079 \\
\hline Mean (SD) & $4.29(0.688)$ & $6.69(0.104)$ & $2.02(0.156)$ & $1.34(0.033)$ & $3.21(0.147)$ & $2.00(0.145)$ & $3.83(5.26)$ & $0.382(0.676)$ \\
\hline
\end{tabular}
This difference indicated that this corn was relatively

Table 1. Apparent geometric mean diameter (GMD), geometric standard deviation (GSD) and change in percent breakage of feed pellets and shelled corn during repeated handling. [a]

[a] Feed pellets and shelled corn differed significantly in GMD, GSD, GSD ${ }_{\mathrm{w}}$, and change in \% breakage at the $5 \%$ level of significance. Negative values of change in $\%$ breakage are due to inherent variability in the materials. 


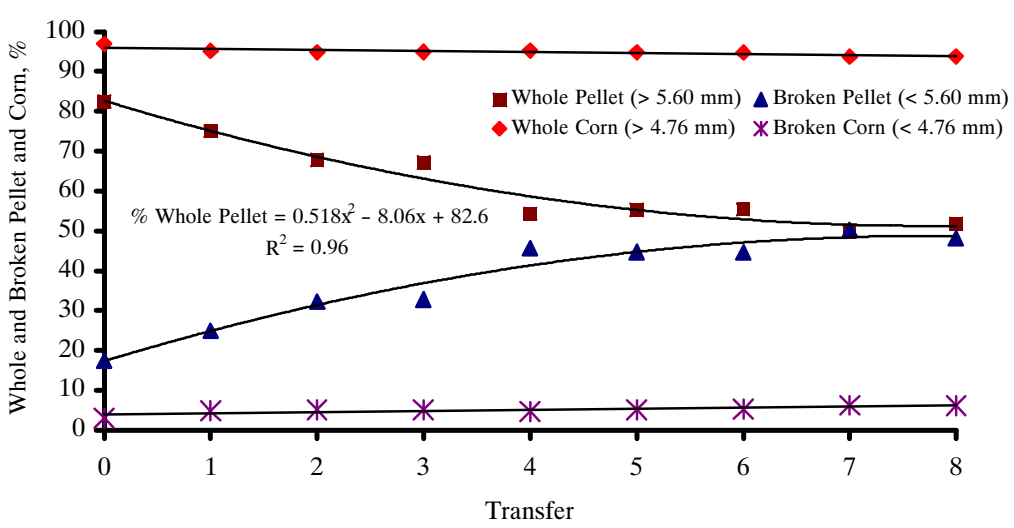

Figure 2. Whole and broken feed pellets and shelled corn (in percentage of total mass) during repeated handling.

durable, which is typical for corn that did not undergo high temperature drying.

The least-squares best-fit line showed a second-order polynomial relationship between number of transfers and broken pellets or whole pellets, with a coefficient of determination, $\mathrm{R}^{2}=0.96$ (fig. 2). This relationship was expected because the weaker pellets break easily and faster during the earlier transfers.

Zatari et al. (1990) indicated that broilers fed $75 \%$ whole pellets and $25 \%$ broken pellets, as compared with $25 \%$ whole and $75 \%$ broken, had better feed efficiency and higher body weight. For this study, a percentage of whole pellets of $75 \%$ or better was attained up to Transfer 1 only; the percentage of whole pellets decreased to approximately $50 \%$ as the final transfer was reached. Amornthewaphat et al. (1999) found a linear decrease in efficiency of growth of finishing pigs as broken pellets was increased from $0 \%$ (7\% greater gain/feed than meal control) to $50 \%$ (2\% greater gain/feed than meal control). In this study, $50 \%$ broken pellets occurred after Transfer 8.

\section{DURABILITY INDEX}

The initial PDI value (Transfer 0 ) for the feed pellets was 92.8\% ( $\mathrm{SD}=1.1 \%)$. For Transfers 1,4 , and 7, the mean PDI values were $92.0 \%(\mathrm{SD}=1.5 \%), 93.3 \%(\mathrm{SD}=0.2 \%)$, and 93.4\% (SD $=2.0 \%)$, respectively. The PDI values increased only slightly and transfers were not significantly different $(\mathrm{p}$ $>0.05$ ). Shelled corn had mean DI values of $99.8 \%$ for Transfers $0,99.7 \%$ for Transfer 1 , and $99.6 \%$ for both Transfers 4 and 7 . The corn DI values for the transfers were not significantly different $(\mathrm{p}>0.05)$ (table 2$)$. The PDI and

Table 2. Durability indices of feed pellets and shelled corn during repeated handling. ${ }^{[a]}$

\begin{tabular}{ccc}
\hline & \multicolumn{2}{c}{ Durability Index $(\%)$} \\
\cline { 2 - 3 } Transfer & Feed Pellets & \multicolumn{1}{c}{ Corn } \\
\hline 0 & $92.8(1.12)$ & $99.8(0.060)$ \\
1 & $92.0(1.51)$ & $99.7(0.080)$ \\
4 & $93.3(0.200)$ & $99.6(0.080)$ \\
7 & $93.4(1.97)$ & $99.6(0.060)$ \\
\hline Mean (SD) & $92.9(0.633)$ & $99.7(0.081)$ \\
\hline
\end{tabular}

[a] Mean durability index of feed pellets was significantly different from that of shelled corn at the $5 \%$ level of significance. corn DI, however, were significantly different from each other $(\mathrm{p}<0.05)$.

Dozier (2001) reported that minimum PDI values differ for different meat birds: $96 \%$ for ducks, $90 \%$ for turkeys, and $80 \%$ for broilers. Hanrahan (1984) reported no difference in finishing pig performance between pigs restrictedly fed pellets with PDI of $69 \%$ or $62 \%$. The feed pellets in this study have nominal size suitable for pigs. This pellet has a higher measured PDI and, based on that PDI, can be expected to give similar or better performance in swine compared to the pellet reported by Hanrahan (1984).

Aarseth (2004), who compared three types of feed pellets: FF30, FE, and KN, indicated that the pellet with highest bulk density (BD) was also the least susceptible to attrition in the Holmen pellet tester. The BDs of the FE and FF30 tested for $120 \mathrm{~s}$ in the Holmen tester were 641 and $664 \mathrm{~kg} / \mathrm{m}^{3}$ and the PDIs were $92 \%$ and $96 \%$, respectively. The KN pellet, which was tested for $30 \mathrm{~s}$, had BD $=623 \mathrm{~kg} / \mathrm{m}^{3}$ and PDI $=94 \%$. The feed pellets in this study had a BD of $644 \mathrm{~kg} / \mathrm{m}^{3}$ and initial PDI of 92.8\%, which is comparable to FE in Aarseth's study. It should be noted, however, that the Holmen tester seemed to be harsher than the tumbling box method, and therefore would yield lower PDI values (Winowiski, 1998). The feed pellets in this study may have a lower PDI value if tested with the Holmen tester.

\section{DusT}

The mean percentage of pellet dust collected by the cyclones was $0.694 \mathrm{~kg} / \mathrm{t}$ of pellet mass. Shelled corn had mean collected dust of $0.614 \mathrm{~kg} / \mathrm{t}$ of corn mass, which was not significantly different from that of the feed pellets $(p>0.05)$ (table 3).

The mean mass of dust $<0.125 \mathrm{~mm}$ per unit mass of pellets $(0.337 \mathrm{~kg} / \mathrm{t}$ of pellet mass) was significantly different $(\mathrm{p}<$ $0.05)$ from that of shelled corn $(0.403 \mathrm{~kg} / \mathrm{t}$ of corn mass) (table 3). Overall, the mass of dust $<0.125 \mathrm{~mm}$ for the feed pellets was $50 \%$ of the total dust collected, which was significantly different from that of corn $(66 \%$ of the total dust) in this study.

Compared with published values, the mean percentages of dust of both feed pellets ( $0.069 \%$ of pellet mass) and shelled corn $(0.061 \%$ of corn mass) were significantly different from that of Martin and Stephens (1977) (0.082\% of corn mass) for the eight transfers $(\mathrm{p}<0.05)$. The percentages of dust of both materials in this study were also less than that from Martin 
Table 3. Mean total collected dust and calculated amount of dust $<0.125 \mathbf{~ m m}$ of feed pellets and shelled corn during repeated handling.

\begin{tabular}{|c|c|c|c|c|}
\hline \multirow[b]{2}{*}{ Transfer } & \multicolumn{2}{|c|}{$\begin{array}{c}\text { Total Collected Dust } \\
\text { (kg/ t of materials handled) }\end{array}$} & \multicolumn{2}{|c|}{$\begin{array}{c}\text { Collected Dust }<0.125 \mathrm{~mm} \\
(\mathrm{SD}) \\
(\mathrm{kg} / \mathrm{t} \text { of materials handled })\end{array}$} \\
\hline & Feed Pellets & Corn & Feed Pellets & Corn \\
\hline 1 & 0.629 & 0.529 & $0.312(0.022)$ & $0.374(0.024)$ \\
\hline 2 & 0.718 & 0.816 & $0.341(0.004)$ & $0.477(0.017)$ \\
\hline 3 & 0.681 & 0.593 & $0.332(0.004)$ & $0.397(0.023)$ \\
\hline 4 & 0.706 & 0.710 & $0.329(0.006)$ & $0.452(0.014)$ \\
\hline 5 & 0.674 & 0.522 & $0.325(0.002)$ & $0.392(0.012)$ \\
\hline 6 & 0.838 & 0.666 & $0.413(0.017)$ & $0.453(0.028)$ \\
\hline 7 & 0.516 & 0.541 & $0.237(0.003)$ & $0.370(0.021)$ \\
\hline 8 & 0.793 & 0.532 & $0.406(0.013)$ & $0.309(0.020)$ \\
\hline $\begin{array}{l}\operatorname{Mean}[\mathrm{a}] \\
(\mathrm{SD})\end{array}$ & $\begin{array}{l}0.694 \mathrm{~b} \\
(0.099)\end{array}$ & $\begin{array}{l}0.614 b \\
(0.108)\end{array}$ & $\begin{array}{l}0.337 \mathrm{c} \\
(0.053)\end{array}$ & $\begin{array}{l}0.403 \mathrm{~d} \\
(0.055)\end{array}$ \\
\hline
\end{tabular}

[a] Means (within the same parameter) with the same letter were not significantly different at the $5 \%$ level of significance.

and Lai (1978), which was $0.095 \%$ of the corn mass. The shelled corn from this study was relatively cleaner than that of Martin and Stephens (1977) and Martin and Lai (1978).

The amounts of dust $<0.125 \mathrm{~mm}$ in Martin and Stephens' (1977) shelled corn (70\% of the mass of the dust) and in Martin and Lai's (1978) shelled corn (85\% of the mass of dust) were greater than that from the pellets $(50 \%)$ and shelled corn $(66 \%)$ from this study. The percentage of dust $<0.125 \mathrm{~mm}$ of the pellet was significantly different $(\mathrm{p}<0.01)$ from that of Martin and Stephens' (1977) shelled corn.

An increase in the mass of pellet dust $<0.125 \mathrm{~mm}$ during the eight transfers was observed, as shown in table 3. Martin and Stephens (1977) also observed an initial increase in the amount of corn dust $<0.125 \mathrm{~mm}$ emitted in the first eight transfers, while the amount of dust $<0.125 \mathrm{~mm}$ became constant during subsequent transfers.

\section{Conclusions}

Feed pellets made from corn meal were tested for durability and breakage during repeated handling in a research grain elevator. Similar tests were conducted with shelled corn for comparison. Each material was transferred alternately between two storage bins, for a total of eight transfers. The following conclusions were drawn from the research:

- Repeated handling did not significantly affect the durability index of the feed pellets, which ranged from $92.0 \%$ to $93.4 \%$, nor that of shelled corn, which ranged from $99.6 \%$ to $99.8 \%$.

- The percentage of broken pellets $(<5.60 \mathrm{~mm})$ increased from an initial value of $17.5 \%$ to $50.2 \%$ after eight transfers, an average percentage increase in breakage of $3.83 \%$. The percentage of broken corn increased from $3.13 \%$ to $6.18 \%$; the average percentage increase was $0.38 \%$.

- The average mass of dust removed per transfer was $0.069 \%$ of the mass of pellets, which was not significantly different from that of shelled corn $(0.061 \%)$ but was significantly different from that reported by Martin and Stephens (1977) for a different lot of corn.
- Overall, $50 \%$ of pellet dust collected in the cyclones were $<0.125 \mathrm{~mm}$ in diameter, which was a smaller percentage than that collected with shelled corn $(66 \%)$. The mean mass of dust $<0.125 \mathrm{~mm}$ of the pellets $(0.337 \mathrm{~kg} / \mathrm{t}$ of pellet mass) was significantly less $(\mathrm{p}<0.05)$ than that of shelled corn $(0.403 \mathrm{~kg} / \mathrm{t}$ of corn mass), indicating that these pellets produced less dust in the range of 0.01 to $0.125 \mathrm{~mm}$ during handling than did shelled corn.

\section{ACKNOWLEDGEMENTS}

The research was supported by USDA (CRIS No. 5430-43440-005-00D) and by the Kansas Agricultural Experiment Station (Contribution No. 06-354-A). The technical support of Prof. Fred Fairchild (KSU) and Dr. Keith Behnke (KSU) and the assistance provided by Mr. Dennis Tilley (GMPRC), Jay St. Clair (GMPRC), Haidee Gonzales (KSU), and Li Guo (KSU) in conducting the experiments are highly appreciated. We also thank the Grain Science and Industry Department of Kansas State University for the use of the pellet durability tester.

\section{REFERENCES}

Aarseth, K. A. 2004. Attrition of feed pellets during pneumatic conveying: the influence of velocity and bend radius. Biosystems Engineering 89(2): 197-213.

Aarseth, K. A., and E. Prestløkken. 2003. Mechanical properties of feed pellets: Weibull analysis. Biosystems Engineering 84(3): 349-361.

Adapa, P. K., L. G. Tabil, G. J. Schoenau, and S. Sokhansanj. 2004. Pelleting characteristics of fractionated sun-cured and dehydrated alfalfa grounds. Applied Engineering in Agriculture 20(6): 813-820.

Amornthewaphat, N., J. D. Hancock, K. C. Behnke, R. H. Hines, G. A. Kennedy, H. Cao, J. S. Park, C. S. Maloney, D. W. Dean, J. M. Derouchey, and D. J. Lee. 1999. Effects of feeder design and pellet quality on growth performance, nutrient digestibility, carcass characteristics, and water usage in finishing pigs. $J$. Anim. Sci. 77(Suppl. 1): 55.

ASAE Standards. 2003a. S269.4. Cubes, pellets, and crumbles definitions and methods for determining density, durability and moisture content. St. Joseph, Mich.: ASAE.

ASAE Standards. 2003b. S319.3. Method of determining and expressing fineness of feed materials by sieving. St. Joseph, Mich.: ASAE.

ASAE Standards. 2003c. S358.2. Moisture measurement - Forages. St. Joseph, Mich.: ASAE.

ASAE Standards. 2003d. S352.2. Moisture measurement Unground grain and seeds. St. Joseph, Mich.: ASAE.

ASTM Standards. 2000. E300-92. Standard practice for sampling industrial chemicals. West Conshohocken, Pa.: ASTM.

Baker, K. D., R. L. Stroshine, K. J. Magee, G. H. Foster, and R. B. Jacko. 1986. Grain damage and dust generation in a pressure pneumatic conveying system. Transactions of the ASAE 29(2): 840-847.

Behnke, K. C. 1994. Processing factors influencing pellet quality. AFMA Matrix. Animal Feed Manufacturers Association. South Africa. Available at http://www.afma.co.za. Accessed 26 April 2005.

Brewer, C. E., P. R. Ferket, and T. S. Winowiski. 1989. The effect of pellet integrity and lignosulfonate on performance of growing toms. Poultry Sci. 68(Suppl. 1):18.

Converse, H. H., and S. R. Eckhoff. 1989. Corn dust emissions with repeated elevator transfers after selected drying treatments.

Transactions of the ASAE 32(6): 2103-2107. 
Dozier, W. A. 2001. Cost-effective pellet quality for meat birds. Feed Management 52(2): 21-24.

Foster, G. H., and L. E. Holman. 1973. Grain breakage caused by commercial handling methods. USDA Res. Serv. Mrktg. Res. Rpt. No. 968. Washington, D.C.: USDA-ARS.

Gustafson, M. L. 1959. The durability test - a key to handling wafers and pellets. ASAE Paper No. 59621. St. Joseph, Mich.: ASAE.

Hanrahan, T. J. 1984. Effect of pellet size and pellet quality on pig performance. Anim. Feed Sci. Technology 10(4): 277.

Jensen, A. H., and D. E. Becker. 1965. Effect of pelleting diets and dietary components on the performance of young pigs. J. Anim. Sci. 24(2): 392-397.

Jensen, L. S., L. H. Merrill, C. V. Reddy, and J. McGinnis. 1962. Observations on eating patterns and rate of food passage of birds fed pelleted and unpelleted diets. Poultry Sci. 41(5): 1414-1419.

Kertz, A. F., B. K. Darcy, and L. R. Prewitt. 1981. Eating rate of lactating cows fed four physical forms of the same grain ration. J. Dairy Sci. 64(12): 2388-2391.

Larsen, T. B., S. Sokhansanj, R. T. Patil, and W. J. Crerar. 1996. Breakage susceptibility studies on alfalfa and animal feed pellets. Canadian Agricultural Engineering 38(1): 21-24.

Martin, C. R., and D. B. Sauer. 1976. Physical and biological characteristics of grain dust. Transactions of the ASAE 19 (4): $720-723$
Martin, C. R., and L. E. Stephens. 1977. Broken corn and dust generated during repeated handling. Transactions of the ASAE 20(1): 168-170.

Martin, C. R., and F. S. Lai. 1978. Measurement of grain dustiness. Cereal Chemistry 55(5): 779-792.

Sokhansanj, S., and W. Crerar. 1999. Development of a durability tester for pelleted and cubed animal feed. SAE 1999-01-2830. Agriculture Machinery, Tires, Tracks, and Traction SP-1474: 83-87.

USDA-GIPSA. 2004. Chapter 4. Corn. In Grain Inspection Handbook, Book II, Grain Grading Procedures. Washington, D.C.: USDA Grain Inspection, Packers, and Stockyards Administration, Federal Grain Inspection Service.

Winowiski, T. S. 1998. Examining a new concept in measuring pellet quality: Which test is best? Feed Management 49(1):23-26.

Young, L. R. 1962. Mechanical durability of feed pellets. Unpublished MS thesis, Manhattan, Kans.: Kansas State University, Department of Grain Science and Industry.

Zatari, I. M., P. R. Ferket, and S. E. Scheideler. 1990. Effect of pellet integrity, calcium lignosulfonate, and dietary energy on performance of summer-raised broiler chickens. Poultry Sci. 69(Suppl. 1):198. 
